\title{
Challenges to sustainable peri-urban settlement development in China: an analysis by empirical evidence in Tianjin
}

\author{
L. Sun ${ }^{1,2}$, C. Li $^{2}$, J. Gwilliam ${ }^{2}$ \& P. Jones ${ }^{2}$ \\ ${ }^{I}$ School of Architecture, Tianjin University, China \\ ${ }^{2}$ Welsh School of Architecture, Cardiff University, UK
}

\begin{abstract}
The world is rapidly urbanizing with the developing world contributing the largest percentage to this process. With urban dispersal as a common phenomenon, peri-urban development becomes critical for understanding urban sustainability. In recent years, peri-urban settlement development in Chinese cities has been put on a fast track, yet its current situation and implications for urban sustainability are little understood. This study discusses three recently planned and developed settlement cases in the city periphery of Tianjin, China, all of which lay claim to certain facets of sustainability. Based on the empirical findings, current and emerging challenges to sustainability are discussed and suggestions for the complementary approaches and progression in the planning and management of peri-urban settlements are proposed.
\end{abstract}

Keywords: peri-urban, settlement development, China, sustainability.

\section{Introduction}

The world is rapidly urbanizing with the developing world contributing the largest percentage to this process. With spatial expansion induced by urban population growth taking place in almost every megacity, a type of spatiality referred to as the "peri-urban" has emerged as a new research agenda for urban studies. The peri-urban interface is "where rural and urban features co-exist, in environmental, socio-economic and institutional terms" [1]. Its interlinked nature with both the urban and the rural means that the evaluation of sustainability in this context requires inquiry into its environmental, social and economic dimensions, as well as benefiting both the urban and the rural contexts. In recent 
years, peri-urban settlement development in Chinese cities has been put on a fast track, yet its current situation and implications for sustainability are little understood. This study discusses three recently planned and developed periurban settlement cases in Tianjin, China, all of which lay claim to certain facets of sustainability. An analysis was carried out on the studied cases, covering six separate yet interlinked themes: natural environment; accessibility; agricultural land; employment and well-being; social cohesion; and public participation. Based on the empirical findings, current and emerging challenges to sustainability are discussed and suggestions for the complementary approaches and progression in the planning and management of peri-urban settlements are proposed. This study seeks to make contributions both to the peri-urban theoretical conceptualizations and empirical research in the context of sustainability. Infused in the explanation of the study cases is the information obtained from site visits during 2009 and 2010. Methods include, personal observations, informal discussions, semi-structured and open-ended interviews with local officials, planners, real estate developers, community management bodies as well as residents of the areas studied.

\section{Peri-urbanization in China and its implications for the sustainability agenda}

China has embarked on a fast track of peri-urbanization since the early 1980s, when economic reforms diverted policy towards encouragement of rural industrialization and urbanization. The relocation and expansion of industries and settlements into the urban periphery have been induced by the growing economy and explicitly supported by public policy, as the development of "raw land" in the suburbs has become a major source of local government revenue [2]. In recent years, the negative impacts of increased decentralization of urban settlements were realised, with agricultural lands being converted to nonagricultural purposes at an unprecedented speed. This has not only caused considerable degradation of the rural environment but also exerted great pressure on existing city supporting systems. Furthermore, the centrally-led and often enforced, requisition of farmland has created millions of landless farmers. With their social security being previously exclusively derived from land ownership, landless farmers are vulnerable to impoverishment [3]. Further, their limited education attainment and skills limits their ability to compete for urban-based employment [4]. Since 2006, new restrictions have been enforced on nonagricultural development requiring the requisition of farmland. Innovative land use strategies were thus proposed nation-wide to achieve balance between requisition and re-cultivation of farmland and implementation of rural urbanization with minimum public funds and minimum impact to relocated farmers. Among these, the "Exchange Zhaijidi for Apartment" (EZA, zhaijidi huanfang) programme has gained most attention and support from the authorities, including regional experimental application. Zhaijidi is a piece of land that is collectively owned and granted to rural households to use as the site for their homes. The EZA programme allows exchange of zhaijidi for an 
apartment in a newly-developed conglomerated residential compound. The rationale behind this being that by opting for a more compact form of rural settlement, more land can be released for peri-urban development: partly for agricultural use, thus resolving the conflict between urbanization and the loss of farmland; and partly for commercial/industrial use, income from which can be used to fund the development costs, thus minimizing demand on public funds.

Residential development acts as another important driver of peri-urbanization in Chinese cities, although to a lesser extent than the industrial factor [5]. The clearance of slum settlements out of the city centre has largely contributed to peri-urban residential development. Compared to other developing countries, where the informal sector played a significant role in accommodating the relocated population, China took a centrally-coordinated approach, building large-scale, high-density affordable housing estates in peripheral locations. The cost for which is reduced through such measures as waiving the land compensation fee and reducing other administrative fees, while placing limits on developers' pricing and profit margin. The eligibility of buyers is subject to official approval and is restricted to displaced inner urban residents and lowincome households. In recent years, encouraged by the boom in the commodity housing market and facilitated by increasing personal mobility, commercial housing estates have begun to take the lead in shaping the peri-urban interface. Large property developers, often single-handedly, have shaped these new periurban localities by building large integrated residential complexes with new commercial service centres. These gated communities, that raced to be situated in peri-urban green fields, are essentially privately financed new towns, often featuring Western styles that promise to package a new way of life [6].

To sum up, peri-urbanization in Chinese cities is fundamentally driven by the urge for economic growth and rural urbanization and more recently by residential development associated with inner-urban slum clearance and commercial housing construction. These forces have shaped three distinct new master-planned settlement types for the urban periphery of Chinese cities: rural resettlement projects associated with farmland requisition; real estate development of suburban commercial housing; and affordable housing compounds. The question remains, however, whether they have formed a foundation on which a sustainable urban future can be built? The sustainability agenda provides an important approach to shaping settlements. It proposes that we need to take into account a wide range of issues and integrate the social, economic and environmental goals of society [7]. The interlinked nature of the peri-urban, with both the urban and the rural, means that questions regarding farmland, ecological systems, employment, poverty and the built environment are all interwoven. To understand sustainability in this context thus requires inquiry into a series of issues and their interrelations. In the next section, three recent residential settlement development case studies in the peri-urban areas of Tianjin, China, each representing one of the typologies above, are described, while their different approaches to achieving sustainability are illustrated against their specific socio-economic contexts. 


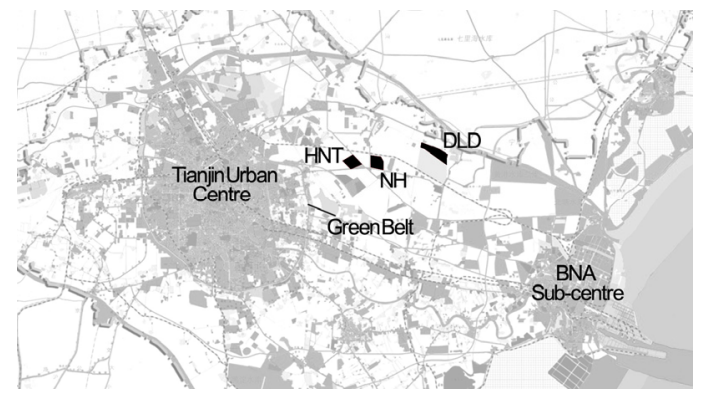

Figure 1: $\quad$ Location of the study cases on the metropolitan map of Tianjin.

\section{Peri-urban settlement development in China: case studies in Tianjin}

Since the early 1980s, Urban Masterplans in major Chinese cities have implemented "decentralized-concentration" growth management, officially encouraging the development of peripheral constellations [8]. As the fifth largest city and one of the four municipalities with provincial-level status, Tianjin's urban development in the post-reform era has followed this model. Spatial expansion in the last three decades has resulted in land within the designated green belt being filled by new urban developments. The current Urban Masterplan strengthens a poly-centric urban structure with a peri-urban industrial port town designated as a secondary urban centre. Between the two urban centres, 14 peri-urban settlements are proposed, to accommodate an additional population of 1.41 million by 2020 . In this section, these recent developments are discussed, using three case studies, all of which are large-scale "flagship" developments proposed and developed in the last 10 years, fig. 1.

\subsection{Case 1: The Dongli Lake Development (DLD)}

The DLD is a commercial housing estate developed by China Vanke Co. Ltd. (Vanke), one of the forerunners in China's embryonic real estate sector. During planning, DLD was to be Vanke's flagship sustainable development project. On a site of 273 hectares, a total floor area of around 800,000 square metres of housing are being developed on the north bank of the Dongli Lake, the largest of seven ecological conservation areas in Tianjin. Starting in 2003, an 8-10 year plan was devised to develop a new town incorporating residential, education, tourism and leisure facilities. In 2005, the site was designated as a "Natural Wetlands Conservation Area (County-level)" [9]. Although construction had begun, Vanke was forced to modify their plans in accordance with the wetland protection requirements. International teams specializing in sustainable engineering and ecological design were invited to inform the new site masterplan, and provide technical and wetland design support. The resulting series of wetlands and open marsh captures and treats the site's storm water, and serves as an aesthetic focal point for the community. A community education 
centre was built at the edge of the marsh to educate people about how the wetland works and the science and engineering behind wetland treatment. DLD was also among the first large-scale housing developments to adopt the new energy-efficient building regulations which came into effect in 2004, stipulating a $65 \%$ energy saving for all new-built housing compared with the 1980 's design standard. By August 2010, the first five phases have been completed, featuring a mixture of housing types from European-style detached villas to 18-storey highrise apartment blocks. A package of community service facilities such as food markets, shops, banks, a clinic, kindergartens and a primary school were also planned for the residents.

\subsection{Case 2: The New Homes Projects (NH)}

In recent years, with rocketing property prices accompanied by inner-urban regeneration, the increasing demand for affordable housing has met with inadequate public funding. In response to criticisms of the pro-profit housing policies and call for government intervention, the Tianjin Municipal Government launched the "New Homes" (NH, “xinjiayuan") programme in March 2007. Ten residential communities are proposed within $5-10 \mathrm{~km}$ of the green belt, requiring an area of 4,824 hectares and housing a total of 819,600 residents by 2017 . The developments form part of the "anju" (meaning "secure homes") project, an affordable housing programme initiated in 1995. The NH developments comprise of $70 \%$ commodity housing and 30\% "anju" housing. Albeit called "communities", their sheer scale is in fact comparable to that of new towns. Huaming $\mathrm{NH}$, the first of the $\mathrm{NH}$ projects, is planned on an area of 345.2 hectares of agricultural land. It incorporates 11 neighbourhoods of 1000-3000 households, each planned with a primary school, kindergartens, local food markets, community centre, clinic, bank, post office and bus terminals. In October 2009, the first two neighbourhoods were completed, each constituting around thirty 11-20 storey apartment buildings, with 2-3 bedroom units of 50-60 square metres each. The construction has been regulated by the 2004 energyefficiency design guidance described previously. Solar collectors have been installed on the roofs to supply all homes with solar powered hot water.

\subsection{Case 3: Huaming New Town (HNT)}

In 2005, the township of Huaming, a suburban township administrating 15 villages on an area of $181 \mathrm{sqkm}$, was appointed as a laboratory for the EZA programme. The programme was directly under the leadership of the Deputy Mayor of Tianjin and its implementation was administered by the local authority of the suburban district of Dongli. HNT, the planned conglomerated settlement, was to follow an "integrated triple-zone" pattern, encompassing: a residential estate with 1.5 million square metres of apartment buildings accommodating 42,000 rural residents relocated from the old township; a 7.3 sqkm industrial park featuring high-tech and innovative industries to the west of the residential estate; and an agricultural zone based on re-cultivation of the reclaimed zhaijidi. 
Construction broke ground in April 2006, and by September 2007, the residential estate had been completed. From the outset, the new settlement resembled a typical metropolitan compound with: residential 5-6 storey building blocks; a few 9 to 11-storey high-rise blocks; and a central commercial street encompassing retail shops, banks, a food market, restaurants and a post office, many of which were relocated village businesses. The social structure of the old township was to be preserved by creating neighbourhoods in the new town that equalled the size of the old villages and allowing the continued operation of previous village committees in these new neighbourhoods. All apartment units in the estate, also built to the 2004 energy efficiency standards, are serviced with solar hot water systems, with a bio-gas system installed for every neighbourhood to provide alternative cooking fuel. By August 2010, over 400 companies had settled in the industrial park. The re-cultivation of zhaijidi started in 2007, and following the levelling of 142 hectares of former zhaijidi, 427 greenhouses have been established, growing vegetables and fruits to sell to the city market all year round. The lease of the industrial park and the agricultural park, together with the rent collected from the commercial properties within the residential estate are estimated to generate 120 million yuan (1yuan=0.09British Pound) of annual revenue for the town government and provide 8000 jobs for its residents. Meanwhile, the local government uses the value-added gains from the land to buy social insurance for the landless farmers, equivalent to a pension of 400 to 500 yuan a month. Public participation was given emphasis in the programme proposal, requiring public hearings at the village level, and overall villager consent before initiation of the programme [10]. Aimed at creating a successful model for the lives of farmers that is "ecological, harmonious and habitable" [11], HNT was exhibited as the Urban Best Practices Area of World Expo 2010.

\section{Discussion: challenges to sustainable peri-urban settlement development in China}

The settlement cases described in the previous section demonstrate new interventions to old problems that exist within rapidly urbanizing cities, i.e. the loss of natural environmental assets, increasing burden on energy and resource use, impoverishment of disadvantaged groups and deteriorating local economic resilience. Their approaches demonstrate traits of sustainable development principles that cover environmental, social, and economic dimensions. The studies that have been conducted in the three chosen development cases reveal that, despite some level of success at achieving their goals, there still remain unresolved problems that pose challenges to environmental integrity, economic vitality and social well-being of these communities. The problems identified can be categorized into six separate but also inter-related themes. They are: natural environment; accessibility; agricultural land; employment and well-being; social cohesion; and public participation. The discussion in the following section is thus presented within the framework set by these themes. Within each theme, the relationship between the environmental, social and economic dimensions are explained within the specific conditions of each study case, their remaining 
challenges to future peri-urban sustainability are analysed and possible solutions are proposed.

\subsection{Natural environment}

The peri-urbanization process has forced millions of the rural population into an urban lifestyle, where the use of space heating, air conditioners, lighting, and other household appliances is expected to increase. Despite the enforcement of more stringent energy-efficiency standards, energy consumption in the residential sector will inevitably rise, posing challenges to China's national strategy for achieving a low carbon future. The increased living costs resulting from this life style transformation from rural self-sufficiency to urban consumerism adds a socio-economic angle to this largely environmental concern. In HNT, concerns over increased daily costs of energy, water and estate maintenance, may induce energy poverty in these lower-income households.

Ecological planning seeks to build upon the ecological characteristics of the site and sustain a healthy and balanced ecosystem. DLD, with its preserved wetlands, circulated water features and concentrated greenery, appears to have formed an independent ecological system. However, it is still a fragile one, as an interview with the estate management company revealed that the maintenance of the greenery and the wetlands requires huge amounts of investment on labourintensive work, and that the company is "losing money" on this in exchange for a pleasing appearance to attract potential home buyers. While it is doubtful that the engineered ecology of DLD can be truly sustainable in environmental and economic terms, there is also the question of whether public assets such as natural wetlands should be appropriated as private development sites. Many scholars have noted the reinforcement of unequal conditions of environmental quality on different social groups as a result of private appropriation of land freezing access to and cancelling ecological functions of natural systems and subjecting lower-income groups to environmental hazards [12]. In the case of DLD specifically, a more sustainable approach would have been to retain open access to the wetlands for public use and engage the municipal government in its maintenance rather than relying solely on the private sector.

\subsection{Accessibility}

In the process of central city regeneration, dilapidated neighbourhoods were transformed into central business districts (CBD) where jobs concentrate and land prices become too high for residential use. This results in neighbourhood displacement to peripheral locations, forcing daily commutes to work and causing increased energy consumption and traffic congestion between the urban core and its suburbs. As observed by Wu and He [13], not only are jobs centrally located but other public services such as schools, hospitals, shopping centres and banks all tend to gather around the urban core while, the peripheral developing residential communities are deprived of convenient access to facilities. All the cases described in this study suffer, to varying extents, from inconvenient access to public services due to their peripheral locations. Of the three cases, HNT fairs 
better than the others due to the continuation of operation of the previous village businesses in the new town and provision of space and policy support for service companies to extend their branches into the new town, thus limiting the need for urban commuting. On the other hand, DLD's developer has struggled with the viability of the proposed facilities due to the low occupancy rate. Indeed this becomes a vicious circle whereby, the inadequate service provision further inhibits potential residents. The current occupants of $\mathrm{NH}$ rely heavily on private car use for basic daily errands as very few planned public facilities are in place. More people have refused to accept $\mathrm{NH}$ as an option for settlement after their urban centre homes have been demolished due to the unaffordable costs associated with the inevitable reliance on private car use. As a result, further NH developments have been put on a hold, questioning the strategy of the use of cheap, peri-urban land for affordable housing development. As is observed in the studied cases, poor accessibility to services plagues all types of peri-urban settlement irrespective of the level of car ownership. Compared with physical production, urban consumer services have been accorded less priority among Chinese urban decision-makers. Furthermore, planned peri-urban settlement developments favour self-enclosed compounds in greenfield sites, that are difficult to integrate with existing communities and infrastructure. As these cases present, the provision of good public transit links, educational facilities, consumer and social services is critical for the sustainability and prosperity of peri-urban communities.

\subsection{Agricultural land}

The loss of arable land has environmental, social and economic implications. It exerts impact on the eco-system, resulting in a reduction of biodiversity and change in micro-climate while depriving the basis for subsistence for farmers and risking food security for China's population. The EZA approach, being experimented at HNT, demonstrates an innovative attempt to resolve these problems. Although much work is still under progress, it is justifiable to assume that a balance can be achieved between agricultural land loss and increased agricultural land, in quantity terms at least. The question that remains unresolved is, however, whether the productivity and ecological quality of the replacement, former zhaijidi will meet the standard required. High-quality re-cultivation requires that the new landscape offers a substitute and an offset for the lost land, and provides a long-term basis as living and economic space for generations to come. The re-cultivation approach taken at HNT is indoor-based using mainly fruit and vegetable greenhouses as opposed to open-air re-cultivation based on soil remediation and re-plantation, thus avoiding many of the uncertainties and costs associated with soil treatment and maintenance. However, the impact on the ecosystem and biodiversity was not mentioned in the initiatives nor assessed during and after the re-cultivation. This infers that the EZA approach was undertaken more from a land-use perspective than an ecological one and overlooked the maintenance of a balanced ecosystem. While there is no doubt that the EZA approach is a big step forward from the uncoordinated requisition of farm land for urban development, its success to offset the adverse effects of 
urban growth remains to be justified through further evidence of long-term food production stability and ecological environment sustainability.

\subsection{Employment and well-being}

The employment problem created by transition from an agricultural-based to industry-based economy cannot be as easily resolved as that of land use. In HNT, the transfer of farm land ownership to the newly-established collective farm factory was on a voluntary basis. However, maintaining the farm was not an easy option for the new town residents and barriers to this include an expensive and long daily commute as well as the low profit available in family-based farming. Therefore most of the resettled families gave up their farms, in exchange for which, they received monetary compensation, calculated according to the yield of their farms. As revealed by an unpublished survey report on farmers' satisfaction with the EZA programme, many respondents expressed dissatisfaction with their future work prospects [14]. Although HNT's town committee has been actively involved in preparing the farmers for non-farming jobs, there seems to be a mismatch between the job opportunities available and the farmers' qualifications, with most still favouring agriculturally based jobs (ibid). Concerns over local employment are also expressed in other peri-urban communities, with the majority of the DLD residents being speculative and holiday home buyers means that they don't work in the local area, partly accounting for the low occupancy rate observed there. For the residents of $\mathrm{NH}$, being relocated to the urban edge from their previous central communities entails long daily commutes or changing of jobs to the periphery, neither of which appears feasible due to the low ownership of private vehicles and the relatively low job availability on the periphery. As is demonstrated by the studied cases, jobs aren't as easily planned as physical construction in a market economy. The centrally-led town-making approach that is prevalent within peri-urban settlement development in Tianjin has shown more success at creating eye-pleasing space than sustaining the well-being of their occupants. It might be time for the urban decision makers to reassess the "topdown" and "all-in-one-go" campaign approach and seek to assist in more spontaneous and "bottom-up" actions leading to peri-urbanization that are based on the genuine need of self-improvement.

\subsection{Social cohesion}

DLD comprises a mix of housing types, albeit market driven rather than by intention, and has included community gardens and out-door activity spaces to accommodate social events, thereby appealing to a variety of people, including speculative real estate investors, holiday home buyers, retired couples and commuting workers. However, the current low occupancy rate due to the large percentage of speculative and second-home buyers has inhibited the creation of the sense of community. The NH, on the other hand, demonstrates homogeneity of housing type, which is predominately small apartment unit in high-rise blocks with few community green areas and activity spaces. Indeed, the physical built environment, as a whole, lacks character. Furthermore, such peripheral 
"affordable housing" communities entail destruction of inner-urban neighbourhoods together with their social bonds. In comparison, the in-situ resettlement at $\mathrm{HNT}$ has achieved more success at preserving traditional neighbourhoods, with village structures being preserved, albeit in new surroundings, and villagers living and working within familiar communities.

\subsection{Public participation}

Public participation is a necessity for social and environmental sustainability in urban planning, focussing attention on stakeholder and public interests [15]. The EZA programme experimented at HNT was intended as a flagship for public participation in rural urbanization with public hearings and consultations being positively embraced among the rural communities, while minimising conflicts between the local authority and the public, common in previous cases of farmland expropriation. However, it was observed that public participation was largely limited to the housing exchange process, with planning and design decision making still dominated by authoritative decision and professional opinion. The NH and DLD showed no specific endeavour in involving local communities in decision making, with agreements of land expropriation signed between the village/town government and the developer. Financial compensation was then distributed to farmers on the condition that they leave their land to move to resettlement housing estates or homes elsewhere. The current institutional setting, political culture and incentive structure demonstrate the traits of the centrally-controlled planned economy that still inhibit wide adoption of true and meaningful public participation in China. The cases studied demonstrate some progress is being made in this respect, yet their limitations show that more work has yet to be done to push things forward. The enforcement of institutional conditions catering for public involvement in urban development could be one way to ensure checks and balances for decision making and give voice to affected parties and individuals.

\section{Conclusion}

Through this case study analysis in Tianjin, some key challenges relating to sustainable peri-urban settlement development have been identified. These are:

1. The impact of urban development on natural ecological systems

2. Inadequate service infrastructure provision and increased reliance on private automobile use

3. The conflict between urban spatial expansion and rural land preservation

4. The need for self-sustained local economy and well-being

5. Lack of social cohesion and sense of community

6. Lack of meaningful public participation in the decision-making process related with planning and design.

Several tentative conclusions can be drawn from the analysis presented here. First, there has been a policy shift towards more "pro-environment" and "propoor" approached in new Chinese peri-urban developments. Sustainable technologies such as solar-hot-water systems and higher energy-efficiency 
building regulations have been widely adopted. The protection of natural resources, especially agricultural land and natural wetlands, has been strengthened through strict state and county level regulation exerting significant impact on local development practice. Meanwhile innovative policies and strategies are being experimented to address the issue of social equity caused both by the historical rural-urban dichotomy and the on-going polarization of society. Nonetheless, "pro-growth" mentality is still strong among state and local authorities, with a persisting drive for economic growth and urbanization notwithstanding environmental and social costs. This implies that China has yet to resolve conflicting national priorities and clarify goals and strategies in line with the sustainable development agenda.

Secondly, as private car ownership is still relatively low, the prospect of availability of local employment is key to peri-urban settlement development decisions. However, settlement plans that entail transformations of rural communities need to be made with caution as the incompatibility of the supply of former rural labours with the demand for skilled workers of the modernized industries remains a huge problem waiting to be solved. While post-industrial countries find it difficult to balance work with comfortable living on the urban edge, in China, the balance is somewhat tilted to the other end. While work location often dominates the choice to live on the edge, comfortable living may be the compromise that needs to be made. With service infrastructure provision lagging behind settlement planning and construction, accessibility to services, all in all, becomes the dominant factor in sustaining peri-urban settlements.

Thirdly, the powerful Chinese government is a double-edged sword in the promotion of sustainable urban development. It has proven to be effective and efficient at enforcing pro-environment regulations, in implementing sustainable design; and at initiating campaign-like re-settlement programmes. On the other hand, the empowerment of the general public remains limited, with the "topdown" approach dominating urban planning in China, inevitably leading to sacrifices of fairness for efficiency. This centralized approach allows few channels for voices from the bottom to make their way up and it overlooks the differences in individuals' needs. Therefore, a "bottom-up" dimension to decision-making has yet to be explored and facilitated to ensure sustainable rural/urban community development. China still has a long way to go in this respect given its current political culture and institutional structure.

And finally, the innovative schemes adopted by the cases studied here, despite laying claim to sustainability, are each found to be promoting only certain facets of the sustainability agenda. It is found that a holistic agenda to achieve sustainability is currently lacking within peri-urban settlement development, an agenda that takes into account current issues and integrates environmental, social, and economic aspects of sustainability. A clear framework, therefore, needs to be structured indicating priorities and goals, drawing out evaluation principles and procedures. Restructuring of the current decision-making system would also need to be implemented in order to set up a successful partnership amongst sectors of the society that includes authority, industry and most importantly, the public. 


\section{References}

[1] Allen, A., Dávila, J. D. \& Hofmann, P., Governance of Water and Sanitation Services for the Peri-urban Poor: A Framework for Understanding and Action in Metropolitan Regions, London: Development Planning Unit, University College London, 2006.

[2] Li, S., \& Huang, Y., Urban Housing in China: Market Transition, Housing Mobility and Neighbourhood Change, Housing Studies, 21(5), pp. 613-623, 2006.

[3] Liu, Y., \& Wu. F., Urban poverty neighbourhoods: typology and spatial concentration under China's market transition-a case study of Nanjing, Geoforum, 37(4), pp. 610-626, 2006.

[4] He, S., Liu, Y., Webster, C., \& Wu, F., Property Rights Redistribution, Entitlement Failure and the Impoverishment of Landless Farmers in China. Urban Studies, 46(9), pp. 1925-1949, 2009.

[5] Webster, D., On the Edge: Shaping the Future of Peri-urban East Asia, Stanford: Asia/Pacific Research Center, Stanford University, 2002.

[6] Wu, F., Gated and packaged suburbia: Packaging and branding Chinese suburban residential development. Cities, 27, pp. 385-396, 2010.

[7] Ellis, G., Planning for Sustainable Settlements, Newtownards: Colourpoint Books, 2002.

[8] Zhao, P., Lü, B., \& Woltjer, J., Conflicts in urban fringe in the transformation era: An examination of performance of the metropolitan growth management in Beijing. Habitat International, 33, pp. 347-356, 2009.

[9] TMUPB, Tianjin Urban Master Plan 2005-2020, Tianjin: Tianjin Municipal Urban Planning Bureau, 2005.

[10] TDRC, Notification of the Guidelines for Public Participation and Ensurance of Peasants' Rights in the Demonstration Model Town. In For the Peasants, By the Peasants: Constructing the New Villages, ed. TDRC. Tianjin: Tianjin Development and Reform Committee, (in Chinese), 2007.

[11] People's Government of Dongli District, Notes on the Implementation of Socialist New Villages. In For the Peasants, By the Peasants: Constructing the New Villages, ed. TDRC. Tianjin: Tianjin Development and Reform Committee, (in Chinese), 2007.

[12] Allen, A., Environmental planning and management of the peri-urban interface: perspectives on an emerging field. Environment and Urbanization, 15(1), pp. 135-147, 2003.

[13] Wu, F., \& He, S., Changes in Traditional Urban Areas and Impacts of Urban Redevelopment: a case study of three neighbourhoods in Nanjing, China. Royal Dutch Geographical Society KNAG, 96(1), pp. 75-95, 2005.

[14] Wang, X., A Survey on Tianjin's Land Reform: farmers agreed but not satisfied, Southern Weekly, (in Chinese), 2008.

[15] Enserink, B., \& Koppenjan, J., Public participation in China: sustainable urbanization and governance. Management of Environmental Quality: An International Journal, 18(4), pp. 459-474, 2007. 